\title{
Reciprocal functional interactions between the brainstem and the lower spinal cord
}

\author{
Itaru Yazawa* \\ Laboratory of Neural Control, National Institute of Neurological Disorders and Stroke, National Institutes of Health, Bethesda, MD, USA
}

\section{Edited by:}

L. Ashley Blackshaw, University of

Adelaide, Australia

Reviewed by:

Lu Liu, University of New South

Wales, Australia

Andrea Harrington, University of

Adelaide, Australia

\section{*Correspondence:}

Itaru Yazawa, Department of Oral

Physiology, Showa University School

of Dentistry, 1-5-8 Hatanodai,

Shinagawa-ku, Tokyo 142-8555,

Japan

e-mail: yazawa-ns@umin.ac.jp
The interplay of the neuronal discharge patterns regarding respiration and locomotion was investigated using electrophysiological techniques in a decerebrate and arterially perfused in situ mouse preparation. The phrenic, tibial, and/or peroneal nerve discharge became clearly organized into discharge episodes of increasing frequency and duration, punctuated by periods of quiescence as the perfusion flow rate increased at room temperature. The modulated sympathetic tone induced by the hyperoxic/normocapnic state was found to activate the locomotor pattern generator (LPG) via descending pathways and generate a left and right alternating discharge during discharge episodes in the motor nerves. The rhythm coupling of respiration and locomotion occurred at a 1:1 frequency ratio. Although the phrenic discharge synchronized with the tibial discharge at all flow rates tested, the time lag between peaks of the two discharges during locomotion was $\approx 400 \mathrm{~ms}$ rather than $\approx 200 \mathrm{~ms}$, suggesting spinal feedback via ascending pathways. The incidence of the phrenic and tibial discharge episodes decreased by $\approx 50 \%$ after spinalization at the twelfth thoracic cord and the respiratory rhythm was more regular. These results indicate that: (i) locomotion can be generated in a hyperoxic/normocapnic state induced by specific respiratory conditions, (ii) the central mechanism regarding entrainment of respiratory and locomotor rhythms relies on spinal feedback via ascending pathways, initiated by the activated LPG generating locomotion, and (iii) the increase in respiratory rate seen during locomotion is caused not only by afferent mechanical and nociceptive inputs but also by impulses from the activated spinal cord producing a locomotor-like discharge via ascending pathways.

Keywords: entrainment, hyperoxic/normocapnic state, locomotion, locomotor pattern generator, respiration

\section{INTRODUCTION}

Entrainment of respiratory and locomotor rhythms during locomotion is well-documented in many species, including rats, cats, rabbits, dogs, and humans (Krogh and Lindhard, 1913; Dejours, 1967; Iscoe, 1981; Bramble and Carrier, 1983; Ainsworth et al., 1996). Such coupling can be evoked by electrical stimulation of either the mesencephalic locomotor region or the subthalamic locomotor region (Bramble and Carrier, 1983; Corio et al., 1993) within a wide range of frequency ratios between locomotion and respiration (e.g., 1:1, 2:1, and 3:2). Although the coordination of respiratory and locomotor rhythms is thought to be generated by central feed forward (Eldridge et al., 1981; Krogh and Lindhard, 1913) and spinal feedback mechanisms (Brice et al., 1988; Brown et al., 1990; Potts et al., 2005; Giraudin et al., 2012), the neural mechanisms involved are poorly understood.

Pickering and Paton (2006) pioneered the use of a decerebrate and artificially perfused rat preparation to investigate brainstem function involved in respiration, circulation, and sympathetic tone, using artificial cardiopulmonary bypass to deliver oxygen to the body. Oxygen consumption goes up with increasing perfusion flow volume, as described in human extracorporeal circulation (Fox et al., 1982; Kirklin and Barratt-Boyes, 1993) presumably metabolism increases as flow rate increases. However, the increase in metabolism is not always reflected in that of neuronal activity and/or the sympathetic tone, it is unclear whether the sympathetic tone resulting from the increase in flow rate can generate unknown autonomic functions.

The present study used a decerebrate and arterially perfused in situ mouse preparation and electrophysiological techniques to investigate (1) whether locomotion can be autonomously generated by a certain sympathetic tone resulting from an increase in flow rate, (2) whether the rhythm coupling of locomotion and respiration can be produced during locomotion. Sequential experiments were performed progressively eliminating influencing (confounding) factors, in an attempt to unravel the central neural mechanisms that mediate the coordination of the respiratory and locomotor rhythms. Neuronal discharges in the phrenic and peroneal and/or tibial nerves were measured, which are considered to reflect the outputs that are derived in the brainstem respiratory center (Barman and Gebber, 1976) and in the spinal networks constituting the locomotor pattern generator (LPG) of the lower spinal cord. Heartbeat and systemic pressure were measured, which are considered to reflect the outputs that are derived in the cardiovascular center of the brainstem (Pickering and Paton, 2006). 


\section{MATERIALS AND METHODS}

Mice were kept in a temperature-controlled room with ad libitum access to food and water. All procedures followed a protocol approved by the National Institute of Neurological Disorders and Stroke/National Institutes of Health Animal Care and Use Committee.

\section{DECEREBRATE AND ARTERIALLY PERFUSED IN SITU MOUSE PREPARATION}

Experiments were performed on 60 male Swiss Webster mice (Taconic Laboratory) aged 5-42 days and weighing 4.6-32.1 g. After initial sedation via inhalation of $5.0 \%$ halothane, an anesthetic combination of ketamine and xylazine (0.5-1.0 $\mu \mathrm{L} / \mathrm{g}$; ketamine:xylazine 7:1) was administered intraperitoneally. During surgery, the halothane concentration was maintained at 1.5-2.0\%, and the depth of anesthesia was assessed by respiratory rate and responsiveness to tail pinch. Mice were placed supine in a dissection chamber and a median laparotomy performed, from the xiphoid to the lower abdomen, for ligation and removal of the stomach, small and large intestines, spleen, pancreas, and their dominant vessels. Using a median sternotomy to open the thorax with a spreading retractor, thoracotomy was performed to allow direct visualization of the heart and lungs. After administration of heparin (10 U/L, intracardiac injection), both the pleura and the pericardium were removed, and the preparation was immediately submerged in Ringer's solution infused with a $95 \% \mathrm{O}_{2}-5 \% \mathrm{CO}_{2}$ gas mixture and maintained at $5-10^{\circ} \mathrm{C}$ to induce suspended animation. The Ringer's solution (composition in mM: $125 \mathrm{NaCl}, 3 \mathrm{KCl}, 24 \mathrm{NaHCO}_{3}, 1.25 \mathrm{KH}_{2} \mathrm{PO}_{4}$, $1.25 \mathrm{MgSO}_{4}, 2.5 \mathrm{CaCl}_{2}$, and $10 \mathrm{D}$-glucose) was maintained at $\mathrm{pH}$ 7.40-7.45 after carbogenation at room temperature (Chizh et al., 1997). After cardiac arrest, craniotomy was performed, with decerebration performed with suction at the precollicular level. Mice were skinned to avoid body fluids accumulating in the subcutaneous tissues. The lungs were then removed and an incision made through the apex of the left ventricle.

While the mouse was held supine in the recording chamber, a double-lumen catheter $(\Phi 1.0 \mathrm{~mm}$, DL-AS-040; Braintree Scientific, MA, USA) was inserted into the heart through the incision in the left ventricle (Figure 1, yellow circle). To ensure that the catheter was securely held in the aortic valve, the outer diameter of the tip was modified to a diameter slightly larger than that of the inner diameter of the value. This modification ensured the perfusate entered the ascending aorta without regurgitation into the left ventricle. Arterial perfusion was immediately initiated with carbogen-gassed, heparinized (10-20 U/L) Ringer's solution containing: Ficoll-70 (1.25-1.28\%) an oncotic agent and penicillin-streptomycin-neomycin $(50 \mathrm{U} / \mathrm{L})$ to prevent infection, at room temperature. Next, an incision was made in the right atrium to maintain the internal pressure of the heart at atmospheric pressure and the incised part of the left ventricle was then sutured ensuring the catheter remained in the ascending aorta.

After resumption of spontaneous breathing at $\leq 15 \mathrm{~min}$ of the initiation of perfusion, the muscle relaxant $d$-tubocurarine $(2 \mu \mathrm{M})$ was added to the perfusate to induce immobilization. The left phrenic nerve was identified and detached from both blood vessels and connective tissues, and severed at the distal end. The left and right peroneal and tibial nerves were then also carefully detached at the knee level and severed at their distal ends. Although bradycardia was pronounced at the initiation of perfusion, ventricular fibrillation never developed.

Using a peristaltic pump (model 323U pump, model 318MC pump head; Watson-Marlow, Wilmington, MA, USA), the perfusate was pumped from a reservoir flask through two bubble traps and a nylon net filter (pore size, $20 \mu \mathrm{m}$; Figure 1). The flow rate was set to $>5 \times$ the total blood volume (TBV) per minute at room temperature, with TBV calculated as $1 / 13$ of the body weight in grams (Mitruka and Rawnsley, 1981; Harkness and Wagner, 1989). Systemic blood pressure was continuously monitored via the second lumen using a strain-gauge pressure transducer (Pressure Monitor BP-1, WPI, FL, USA). All chemicals were purchased from Sigma (St. Louis, MO, USA).

\section{HINDLIMB PREPARATION}

For the hindlimb preparation, 12 male Swiss Webster mice (Taconic Laboratory; aged 14-31 days; weighing 8.5-30.8 g) were used. Decerebrate and arterially perfused in situ preparations (as above) were transected at the fifth thoracic vertebra (Figure 1, green circle). Then, the heart, lungs, and pulmonary artery and vein were removed. For perfusion, a double-lumen catheter (NCV25GW-200W; CMP Inc., Tokyo, Japan) was inserted into the descending aorta through the severed end of the thoracic aorta. After tying the thoracic aorta at the level of the sixth thoracic vertebra to prevent perfusate leakage, arterial perfusion at $5 \times \mathrm{TBV} / \mathrm{min}$ at room temperature was begun. The preparation began to show spontaneous left/right alternating and synchronous movements $\leq 10 \mathrm{~min}$ of perfusion initiation, $d$ tubocurarine $(1-2 \mu \mathrm{M})$ was administered and the left and right peroneal or tibial nerves were detached as described above.

\section{EXTRACELLULAR RECORDINGS}

Suction electrodes constructed of polyethylene tubing (PE 50; Becton, Dickinson and Company, Franklin Lakes, NJ, USA) were used to record neuronal discharge from the left phrenic and the left and right tibial or peroneal nerves. The phrenic nerve suction electrode simultaneously recorded the electrocardiogram (ECG). Phrenic nerve discharge output is considered to be derived from the brainstem respiratory center (Barman and Gebber, 1976). While, changes in heart rate and systemic pressure are indicators of changes of sympathetic tone in the cardiovascular center of the brainstem (Pickering and Paton, 2006). The peroneal and tibial nerve discharges are indicators of the outputs that are generated in the spinal network between the fourth lumbar and third sacral spinal segments and between the fourth lumbar and second sacral spinal segments, respectively. The resultant neurograms were amplified $\times 1000$, filtered at $1-3000 \mathrm{~Hz}$, and digitized using a Digidata $1320 \mathrm{~A}$ and a Clampex (Axon Instruments, Union City, CA, USA) at sampling rates of $10,000 \mathrm{~Hz}$. All data were saved for further analysis.

\section{DATA ANALYSIS}

Spinal Core software (Mor and Lev-Tov, 2007) was used to characterize/quantify the LPG output of the spinal cord induced by signal transmission from the brainstem via descending pathways 


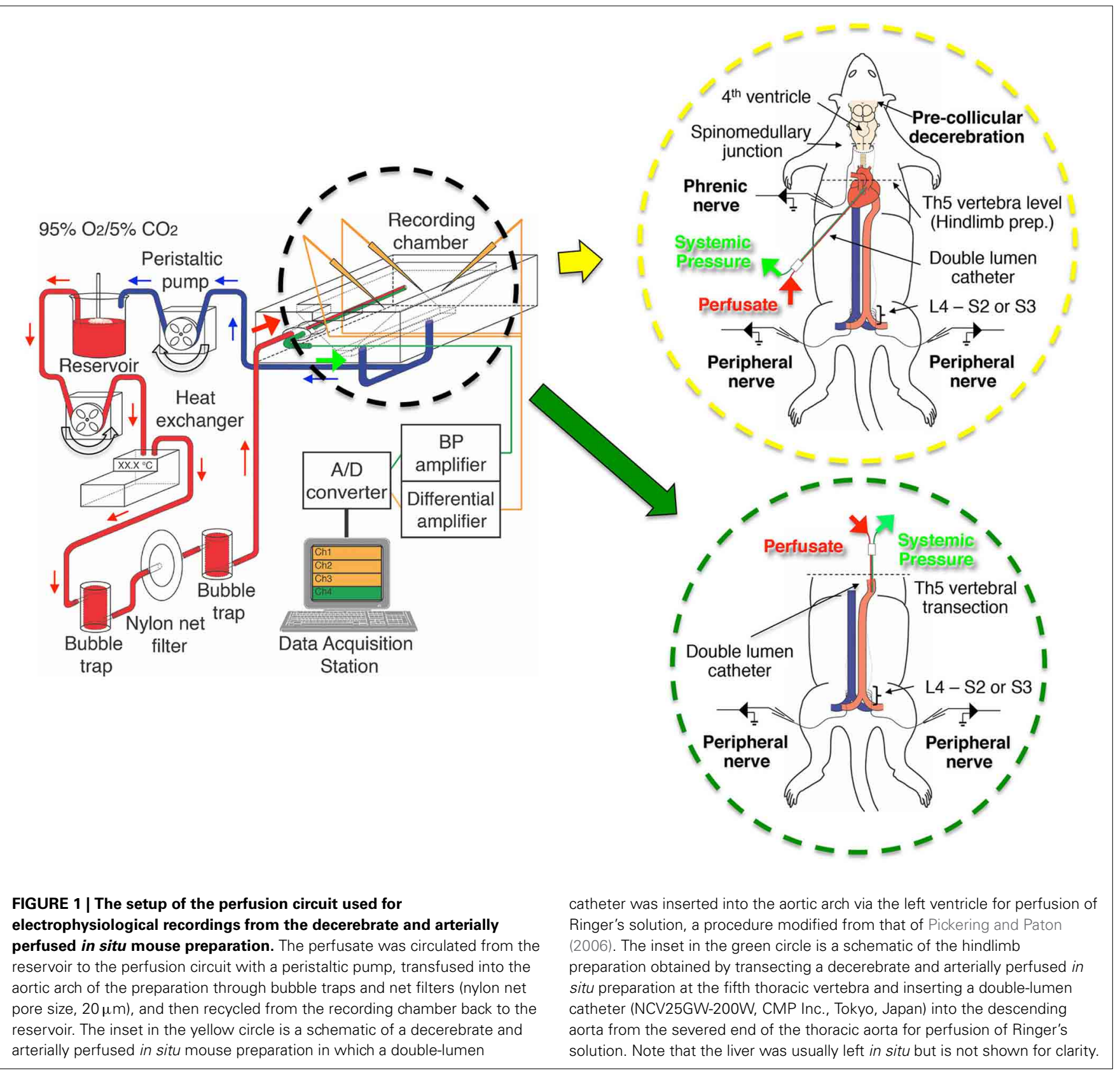

and determine the correlations between the left phrenic and left peripheral muscle nerve discharges and between the left and right muscle nerve discharges during episodes of phrenic nerve discharge. Recorded data were high-pass filtered at $10-20 \mathrm{~Hz}$, rectified, and compressed to a sample rate of $20 \mathrm{~Hz}$. The time series data of left and right tibial nerve discharge and left phrenic and left tibial nerve discharge were used to compute the time domain between the lags from -1 to $1 \mathrm{~s}$ and from -2.5 to $2.5 \mathrm{~s}$, respectively, and develop the correlation curves.

Statistical values are expressed as the mean (SE). Differences between means were analyzed using either a statistical software package (Sigma Stat for Windows; SPSS, Chicago, IL, USA) or excel and assessed by either one factor repeated measures ANOVA with a Scheffe post-hoc or the paired $t$-test. A $P<0.05$ was considered to indicate statistical significance.

\section{RESULTS}

\section{DEPENDENCE OF SYSTEMIC PRESSURE AND PHRENIC AND} PERIPHERAL NERVE DISCHARGE ON PERFUSION FLOW RATE

Although oxygen consumption goes up with increasing perfusion flow volume, as described in human extracorporeal circulation (Fox et al., 1982; Kirklin and Barratt-Boyes, 1993), the increase in metabolism does not always imply an increase in neuronal activity. Thus, the dependence of systemic pressure and phrenic and peripheral nerve discharges on perfusion flow rate was investigated at room temperature. 
Figures 2A1,A2 shows examples of recordings from the left phrenic nerve, left and right peroneal nerves, and systemic pressure, in response to various perfusion flow rates (i.e., differing sympathetic tone). The ECG was obtained from the phrenic nerve recordings. All data were obtained from the same preparation. Both phrenic and peroneal nerve discharge amplitude and frequency increased with increases in flow rate. As the flow rate increased, the phrenic and bilateral peroneal nerve discharges became organized into "discharge episodes" of increasing frequency and duration, punctuated by periods of quiescence. The three discharge episodes were generated approximately at the same time. At flow rates of $<10 \times \mathrm{TBV} / \mathrm{min}$, the left and right peroneal nerve discharges during discharge episodes displayed "burst-like" activity. However, at flow rates of $>10 \times \mathrm{TBV} / \mathrm{min}$, they clearly showed rhythmic activity during discharge episodes. Although the rhythmic activity of the phrenic discharge increased with the increasing flow rates tested, it increased further when phrenic discharge episodes were generated (i.e., phrenic discharge episodes).

I investigated the dependence of heart rate, systemic pressure, amplitude of peripheral motor nerve discharges, and cycle periods of phrenic discharges outside of discharge episodes on perfusion flow rate. Recording periods of $10 \mathrm{~min}$ were set for each flow rate and data recorded during the last $5 \mathrm{~min}$ were used. All data were obtained from five preparations.

In Figure 2B, the mean (SE) amplitudes of the peripheral motor nerve discharges and systemic pressure increased with increased flow rate $\left[F_{(5,4)}=23.696\right.$ and 14.363, $\left.P<0.001\right]$ and significantly increased with each increase in flow rate $(P<0.05)$. Also, the mean (SE) cycle periods of phrenic discharge outside of discharge episodes decreased with increased flow rate $\left[F_{(5,4)}=\right.$ 79.069, $P<0.001]$ and significantly decreased with each increase in flow rate $(P<0.05)$. However, although heart rate significantly increased at $8 \times \mathrm{TBV} / \mathrm{min}(P<0.05)$, it decreased as the flow rate increased further $\left[F_{(5,4)}=3.213, P<0.05\right]$. Interestingly, several small systemic pressure changes were elicited during and after the discharge episodes in the phrenic nerve, including a eupnoeic pattern in the phrenic discharge at all of the flow rates tested. Similar results to those shown in Figure 3B were reproduced in all cases $(n=60)$.

\section{EFFECT OF VAGOTOMY ON PERIPHERAL MOTOR NERVE DISCHARGES DURING DISCHARGE EPISODES}

Vagotomy may contribute to the decrease in the peripheral nerve discharges during discharge episodes because it induces loss of sympathetic tone in the cardiovascular center of the brainstem and increases heart rate (Manning et al., 1963; Bromley and Holdstock, 1969). Although no neuronal discharges in the peripheral motor nerve were produced in the preparation unless the phrenic nerve discharge was generated (data not shown), the discharge episodes in which rhythmic activity was generated in the left phrenic and left and right peripheral motor nerves were produced by increasing the flow rate (Figure 3 ). But it is unclear whether they were affected by loss of sympathetic tone. Thus, the extent to which peripheral nerve discharges during discharge episodes were affected by vagotomy was investigated.
In decerebrate, arterially perfused mice, on postnatal day 10 , the left and right tibial nerve discharges consisting of rhythmic activity during discharge episodes were compared before and after bilateral vagotomy at the cervical level (flow rate $11 \times$ $\mathrm{TBV} / \mathrm{min}$ ). The same pattern of neuronal activity during episodic discharges was seen before and after vagotomy (Figure 3). After vagotomy, the mean (SE) systemic pressure decreased by 7.71 (1.42)\% $(P<0.05)$; the mean peak (SE) amplitude of the left and right tibial nerve discharge during discharge episodes decreased by $13.63(2.34) \%$ and $15.76(2.71) \%(P<0.05)$, respectively; and the mean (SE) duration of the discharge episodes decreased from 11.91 (1.33) to $9.15(1.75) \mathrm{s}(P<0.05)$, whereas the mean (SE) heart rate increased by $10.14(2.5) \%(P<0.05)$. All data were obtained in each of the five preparations at the same flow rate $(11 \times \mathrm{TBV} / \mathrm{min})$. Recording periods of $10 \mathrm{~min}$ were set for each flow rate and data recorded during the last $5 \mathrm{~min}$ were used. These results indicate that the extent of left-right tibial nerve discharges during discharge episodes depends on the sympathetic tone in the brainstem.

\section{PHASE RELATIONSHIPS BETWEEN LEFT AND RIGHT TIBIAL NERVE DISCHARGE DURING DISCHARGE EPISODES}

The phase relationship between the left and right tibial nerve discharge during discharge episodes was investigated. At a flow rate of $12 \times \mathrm{TBV} / \mathrm{min}$, the left and right tibial nerve discharges during discharge episodes assumed a clear left-and-right alternating pattern (Figure 4A1) resembling that induced by administration of serotonin, N-methyl-D,L-aspartate (NMDA), and dopamine to in vitro developing spinal-cord preparations (Whelan et al., 2000). Using the time series data of instances of left and right tibial nerve discharge (underlined data in Figure 4A1), crosscorrelation analysis was used to determine the time lag from -1 to $1 \mathrm{~s}$ between the instances of left and right tibial nerve discharge. Each mean (SE) peak between instances of left and right tibial nerve discharge was characterized by a gap of $497.86(22.82) \mathrm{ms}$ $(r=0.5)$ (Figure 4A2). This result indicates that the frequency of left-right alternating discharge during discharge episodes was $\approx 1 \mathrm{~Hz}$. The mean (SE) frequency of left-right alternating discharge episodes was $1.04(0.01) \mathrm{Hz}$ whenever left-right alternating discharge episodes were generated at the flow rates tested $(>10 \times \mathrm{TBV} / \mathrm{min}$; room temperature) in all cases $(n=60)$.

\section{PHASE RELATIONSHIPS BETWEEN LEFT PHRENIC AND LEFT TIBIAL NERVE DISCHARGE DURING DISCHARGE EPISODES}

During perfusion at a high flow rate $(>10 \times \mathrm{TBV} / \mathrm{min}$; room temperature), the phase relationship between the left phrenic and left tibial nerve discharge during discharge episodes was investigated. Figures 4B1,B2 shows examples of left phrenic and left tibial nerve discharge patterns. In the absence of the discharge episodes, the mean (SE) time lag between peaks of phrenic and tibial nerve discharge was 201.27 (12.74) ms (Figure 4B1 yellow regions). Cross-correlation analysis was performed on the time series data of phrenic and tibial nerve discharge patterns during all discharge episodes to characterize the time lag from -2.5 to $2.5 \mathrm{~s}$ (Figure 4B1). As is shown in Figure 4B2, the mean (SE) time lag between the phrenic discharge and the tibial discharge (peripheral motor nerve discharge) in discharge episodes was 


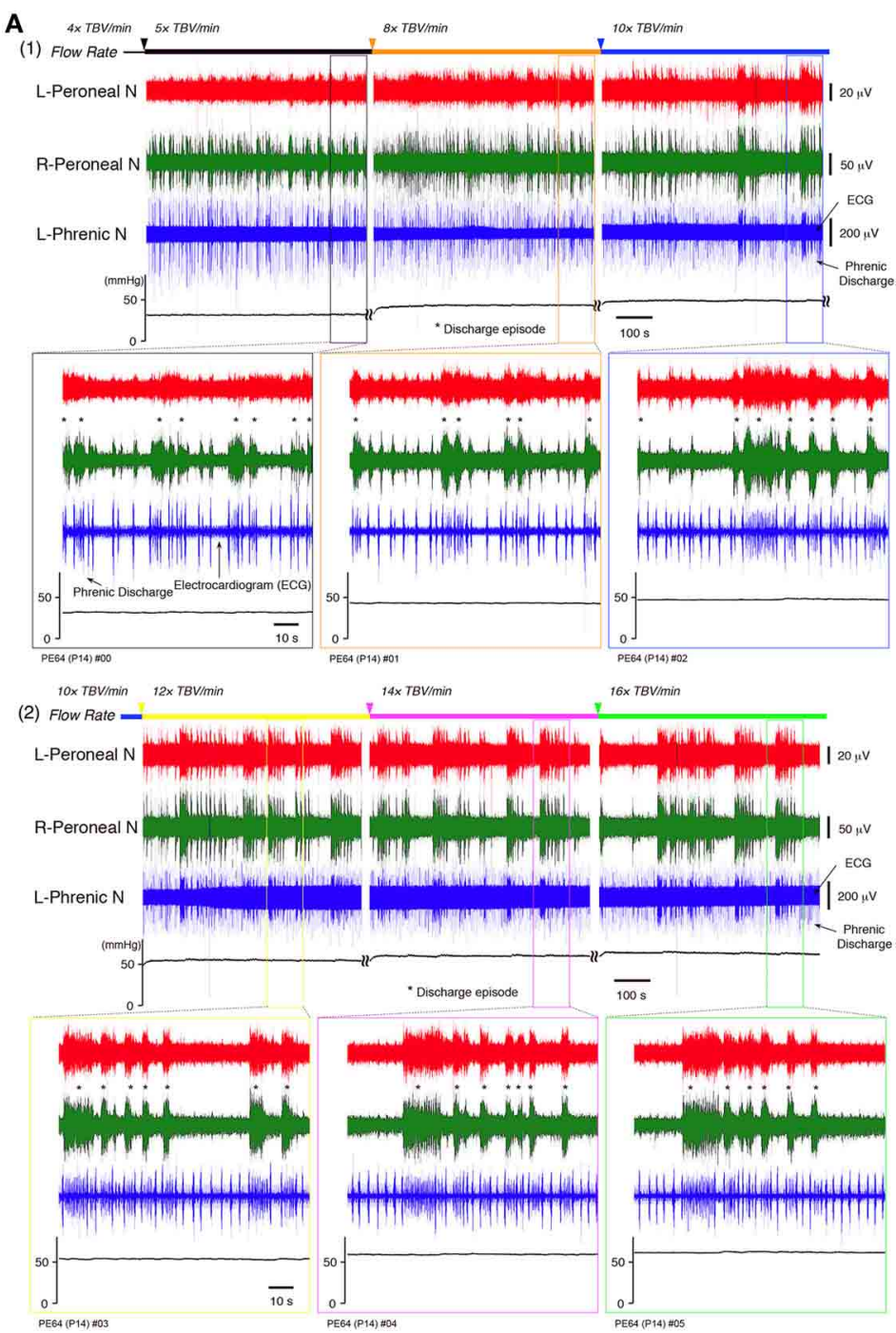

B
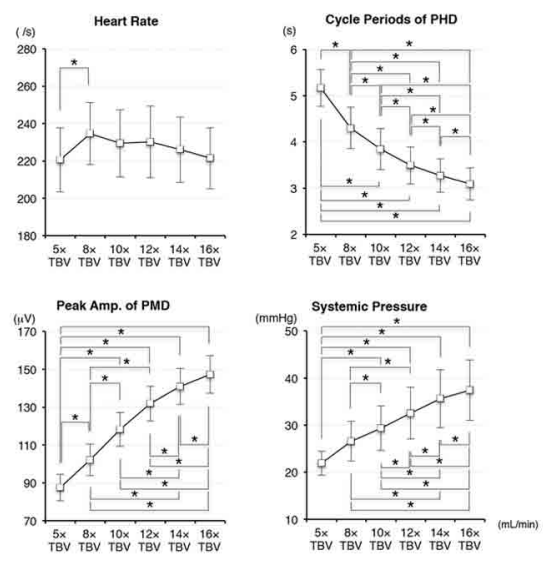

FIGURE 2 | (A) Recordings showing perfusion flow dependence of systemic pressure and phrenic and peripheral nerve discharge in a decerebrate and arterially perfused in situ mouse preparation. (1) Data collected on perfusion flow dependence at $4 \times$ to $10 \times$ and (2) at $12 \times$ to $16 \times$ TBV/min. Phrenic discharge containing the ECG, and left and right peroneal nerve discharge were recorded at the various flow rates at room temperature. The upper panels show the systemic pressure, while the lower panels present an

expanded view of the discharge and systemic pressure of the region surrounding that shown in the upper panels. All data were obtained from the same preparation made at postnatal day 14. As the flow rate increased to $>10 \times \mathrm{TBV} / \mathrm{min}$, the instances of phrenic and left and right peroneal nerve discharge became organized into discharge episodes (asterisks) of increasing incidence and duration punctuated by periods of quiescence. At the same 


\section{FIGURE 2 | Continued}

time, the rhythm of the instances of left/right peroneal and phrenic nerve discharge during each discharge episode became more rapid, and small changes of systemic pressure occurred during discharge episodes. (B) Dependence of heart rate, systemic pressure, amplitude of the peripheral motor nerve discharge (PMD), and cycle periods produced outside of phrenic discharge episodes (PHD) on the flow rate tested. All data were obtained from the five preparations. The mean (SE) amplitude of the PMD and the systemic pressure increased with increased flow rate $\left[F_{(5,4)}=23.696\right.$ and 14.363, $\left.P<0.001\right]$ and significantly increased with each increase in flow rate $(P<0.05)$. The mean (SE) cycle periods of PHD outside of discharge episodes decreased with increased flow rate $\left[F_{(5,4)}=79.069, P<0.001\right]$ and significantly decreased with each increase in flow rate $(P<0.05)$. Although heart rate significantly increased at $8 \times$ $\mathrm{TBV} / \mathrm{min}(P<0.05)$, it decreased as the flow rate increased further $\left[F_{(5,4)}=3.213, P<0.05\right]$.

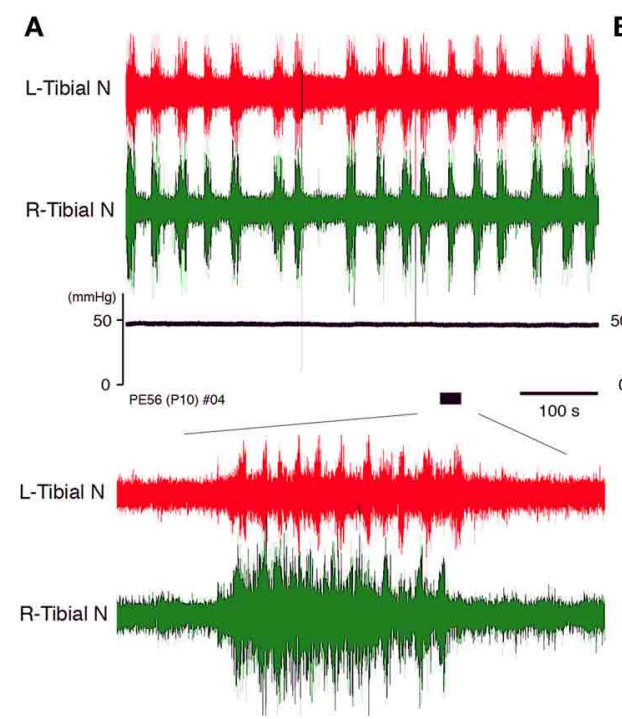

FIGURE 3 | The neuronal discharge and systemic pressure (A) before and (B) after bilateral vagotomy of a decerebrate and arterially perfused in situ preparation made at postnatal day 10 at the cervical level

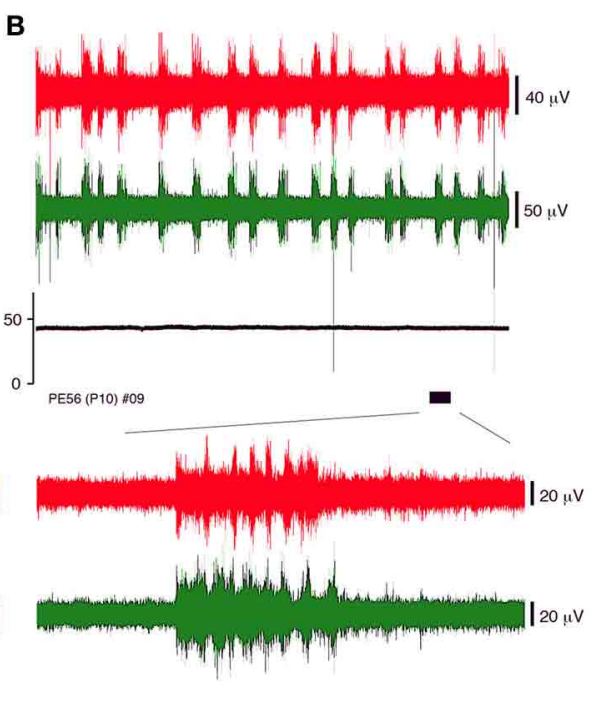

recorded at a flow rate of $11 \times \mathrm{TBV} / \mathrm{min}$. The lower panel provides an expanded view of the underlined portion of the neuronal discharge recording in the upper panel. The same results were obtained in all cases $(n=5)$.
395.17 (19.10) ms (note that the peak is to the right of the vertical dotted line; $r=0.35$ ). This indicates that the coupling of respiratory and locomotor rhythms occurred at about a 1:1 frequency ratio. Similar results to those shown in Figures 4A,B were reproduced in all cases, regardless of the age of the mouse and the experimental conditions $(n=60)$.

\section{EFFECT OF HIGH FLOW RATES ON SYMPATHETIC TONE}

Afferent inputs from peripheral and central chemoreceptors modulate sympathetic/parasympathetic tone in the brainstem (Loeschcke, 1982; O'Regan and Majcherczyk, 1982; Nattie, 1998; Ballantyne and Scheid, 2001). In the present study, the $\mathrm{pH}$ before and after systemic perfusion was maintained within the physiological range, at a mean (SE) of $7.35(0.05)$, in all cases $(n=60)$. Thus, the effect of the impulse originating from the $\mathrm{pH} / \mathrm{PCO}_{2}$ sensor was not examined (as it was assumed not to vary) and the response of the peripheral chemoreceptor to $\mathrm{PO}_{2}$ (O’Regan and Majcherczyk, 1982) was examined as flow rate was increased.

Sodium cyanide $(\mathrm{NaCN} ; 500 \mu \mathrm{M})$, which is known as a chemoreceptor stimulant was applied to the decerebrate and arterially perfused preparations made at postnatal day 15. A chemoreflex and normal phrenic discharge were evoked in all cases (Figures 5A,B) when $0.05 \mathrm{~mL} \mathrm{NaCN}$ was administered at a low flow rate $(6 \times \mathrm{TBV} / \mathrm{min})$. Conversely, a chemoreflex was never induced when a large amount of $\mathrm{NaCN}(0.2 \mathrm{~mL})$ was administered at a high flow rate $(16 \times \mathrm{TBV} / \mathrm{min})$. The results in Figure 5 were obtained from five preparations.

These results and the decrease in heart rate seen at high flow rates (Figure 2B) indicate that loss of chemoresponse in the carotid body was probably due to saturation at high flow rates, as the amount of oxygen delivered to the preparation per unit of time increased with increasing flow rate. Thus, the modulated sympathetic tone induced by a hyperoxic/normocapnic state was found to activate the LPG via descending pathways to spontaneously produce a 'locomotor-like' discharge in the hindlimbs.

\section{CENTRAL MECHANISM(S) OF THE ENTRAINMENT OF RESPIRATORY AND LOCOMOTOR RHYTHMS DURING DISCHARGE EPISODES Origin of the discharge episodes in the decerebrate and perfused preparation}

In general, respiratory rate decreases in a hyperoxic/normocapnic state at rest, but in the present preparation, respiratory rate increased even in a hyperoxic/normocapnic state (Figure 5B). Simultaneously, locomotor-like discharges were seen in the left and right tibial nerves during discharge episodes (Figure 4A). Furthermore, the time lag between phrenic and 


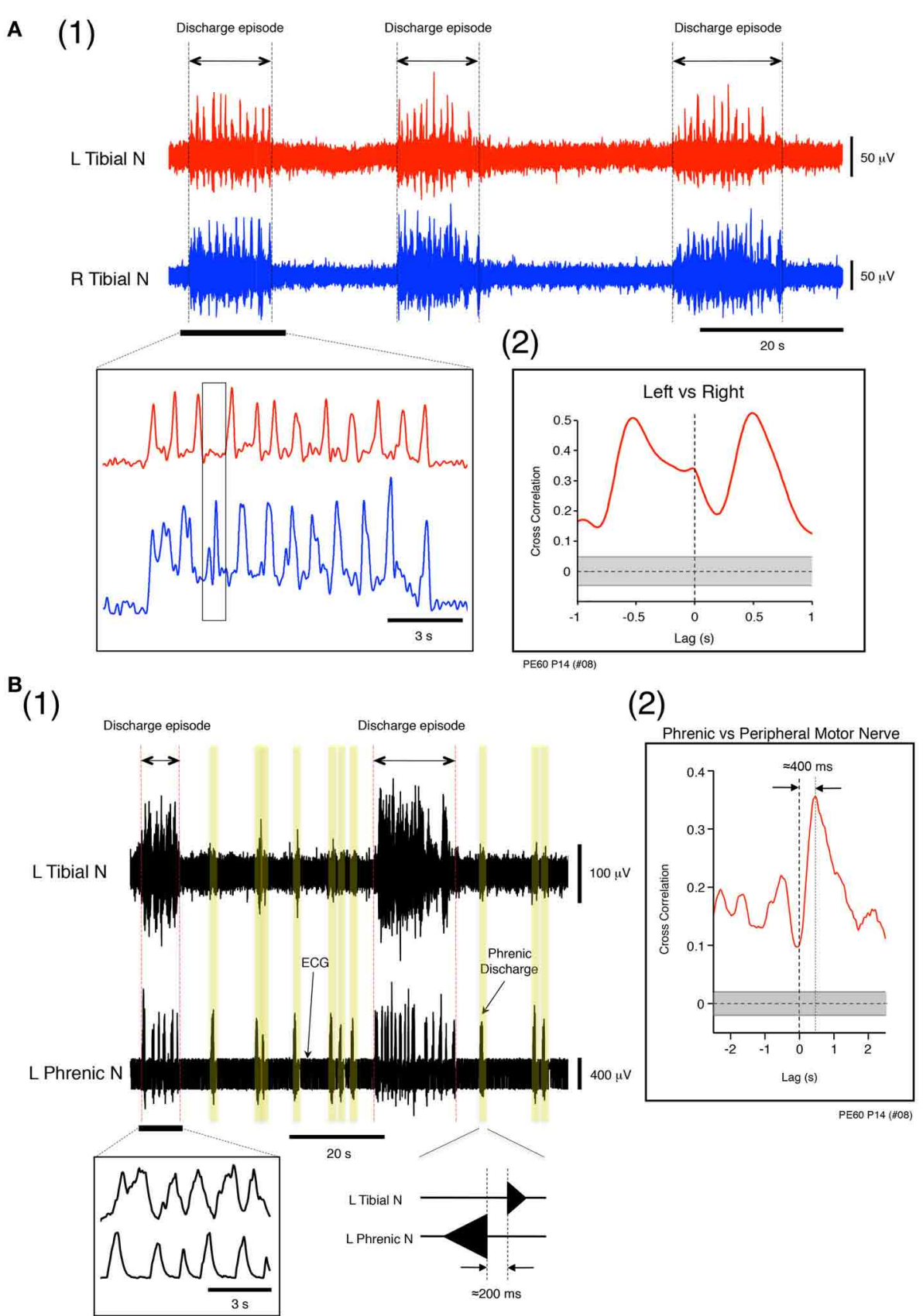

FIGURE 4 | (A) Left and right tibial nerve activity at a flow rate of $12 x$ TBV/min. (1) Recording showing the organization of neuronal activity into discharge episodes punctuated by quiescence. The results of rectification of the neuronal discharge episode appearing in the underlined part of the upper panel are shown in the left lower panel. The speed of the left and right alternating discharge was $<2 \mathrm{~Hz}$. (2) Recording showing correlation between instances of left and right tibial nerve discharge during discharge episodes. To determine the time lag between the two types of discharge during discharge episodes and the correlation in the time domain between lags from -1 to $1 \mathrm{~s}$, time series data for the instances of left and right tibial nerve discharge during discharge episodes were obtained from the underlined data in the upper panel of (1). In (2), the left tibial nerve discharge positioned the right tibial nerve discharge to the right of vertical dotted line, and the right tibial nerve discharge positioned the left tibial nerve discharge to the left of the vertical dotted line. Each peak between the two gapped at $\approx 0.5 \mathrm{~s}(r=0.5)$.
The vertical dotted line denotes zero phase lags. The gray region represents the confidence bounds, which enclose only lags in samples that were not significantly correlated. (B) Left phrenic and left tibial nerve activity at a flow rate of $12 \times \mathrm{TBV} / \mathrm{min}$. (1) Instances of neuronal discharge organized into discharge episodes during which phrenic nerve discharge was synchronous with tibial nerve discharge and punctuated by periods of quiescence. Between discharge episodes, the time lag between instances of phrenic and the tibial nerve discharge (yellow regions) was $\approx 200 \mathrm{~ms}$. (2) Results of cross-correlation analysis of left phrenic and left tibial nerve discharge (peripheral motor nerve discharge) during discharge episodes to determine the time lag between the two types of discharges. The time series data for phrenic and tibial nerve discharge were obtained from all discharge episodes observed in (1) at this flow rate $(12 \times \mathrm{TBV} / \mathrm{min})$. One experiment was performed at the flow rate for $10 \mathrm{~min}$, and most data for time-series episodes (Continued) 


\section{FIGURE 4 | Continued}

were extracted from the data collected from one experiment. Cross-correlation analysis of left phrenic and left tibial nerve discharge during discharge episodes and computation of the correlation in the time domain between lags from -2.5 to $2.5 \mathrm{~s}$ were also performed. In (2), the phrenic discharge positioned the tibial discharge to right of the vertical dotted line, and the time lag between the two types of discharge within episodes was $\approx 400 \mathrm{~ms}(r=0.35)$. The vertical dotted line denotes zero phase lags. The gray region represents the confidence bounds, which enclose only lags in samples that are not significantly correlated. Note that the results shown in (A) and (B) were obtained from the same preparation made at postnatal day 14 .

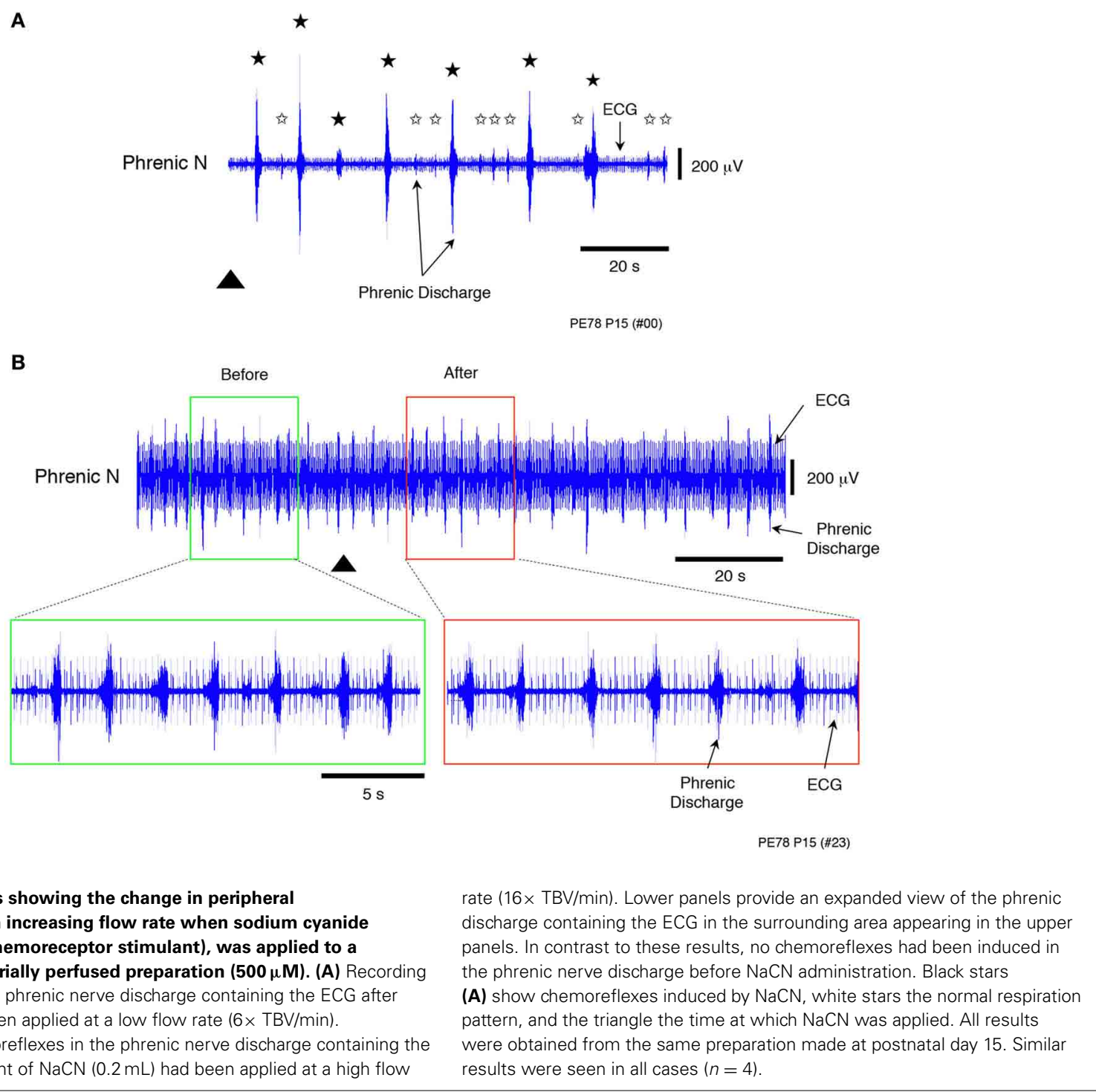

tibial nerve discharge during discharge episodes was $\approx 400 \mathrm{~ms}$ but not $\approx 200 \mathrm{~ms}$ (Figure 5B). These results led me to hypothesize that the mechanism(s) of increased respiratory rate during locomotion relies not only on input from the $\mathrm{pH} / \mathrm{PCO}_{2}$ (Loeschcke, 1982; O'Regan and Majcherczyk, 1982; Nattie, 1998) and $\mathrm{PO}_{2}$ (Nattie, 1998) sensors (the central chemoreceptor and peripheral chemoreceptors, respectively) but also on other forms of input from the lower spinal cord. To test this hypothesis, a hindlimb preparation was developed to investigate whether the discharge episode obtained from the peripheral motor nerve (Figures 2, 4A) was produced by the lower spinal cord itself.
To induce the discharge episodes and/or burst-like discharge episodes shown in Figures 2, 4 in the lower spinal cord, high concentrations of serotonin, NMDA, and dopamine were applied to the hindlimb preparation at postnatal day 15 at a flow rate of $7 \times \mathrm{TBV} / \mathrm{min}$, while neuronal discharge was recorded from the left and right peroneal nerves (Figure 6A). Administration of $160 \mu \mathrm{M}$ serotonin, $80 \mu \mathrm{M}$ NMDA, and $160 \mu \mathrm{M}$ dopamine resulted in the generation of discharge episodes consisting of instances of rhythmic activity induced simultaneously and periodically on the left and the right sides, punctuated by periods of quiescence. With the rhythmic activity induced in the left and 


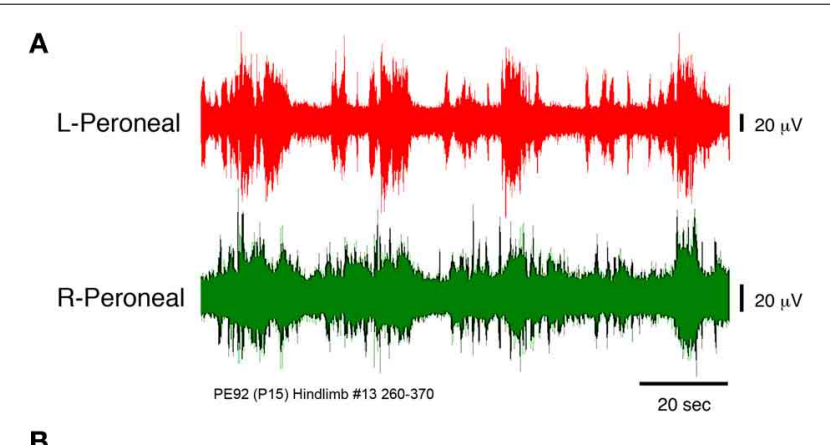

B

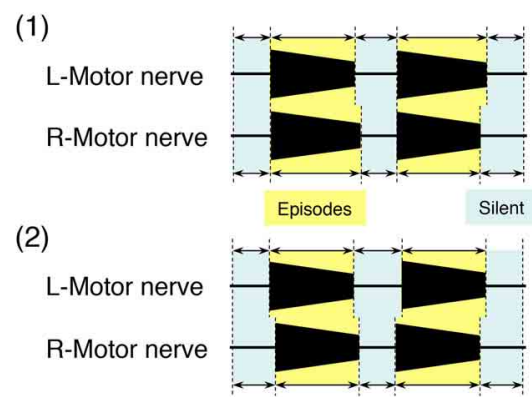

FIGURE 6 | (A) Recordings showing the instances of left and right peripheral motor nerve discharge episodes induced by administration of high concentrations of serotonin, $\mathrm{N}$-methyl-D, L-aspartate, and dopamine to a hindlimb preparation made at postnatal day 15. Neuronal discharge was recorded from the left and right peroneal nerves at a flow rate of $7 \times$ $\mathrm{TBV} / \mathrm{min}$. After administration of $160 \mu \mathrm{M}$ serotonin, $80 \mu \mathrm{M}$

$N$-methyl-D, L-aspartate, and $160 \mu \mathrm{M}$ dopamine, neuronal discharges became organized into episodes punctuated by periods of quiescence. The discharge episodes were induced simultaneously and periodically on both sides. Individual neuronal discharge episode consisted of a rhythmic and/or burst-like activity that occurred at various frequencies. The rhythmic discharge episode in the left and right peroneal nerve showed a left-right alternating pattern. The same result was obtained in all 12 hindlimb preparations. (B1) Schematic of the episodic pattern of discharge episodes, based on the discharge episode in Figures 3, 4A, produced at a high flow rate in a decerebrate and arterially perfused preparation. (B2) Schematic of the episodic pattern of discharge episodes, based on the discharge episode in (A), induced by the administration of drugs to the hindlimb preparation. Periods in which discharge episodes were obtained in each nerve were defined as episodic periods and those in which no discharge episode was obtained were defined as silent periods. Both episodic and silent periods were recorded for each preparation and occurred simultaneously and repeatedly on both sides. Both episodic patterns were similar.

right peroneal nerve discharge showing a left-right alternating pattern. The same result was obtained at high concentrations of serotonin $(60-160 \mu \mathrm{M})$, NMDA $(30-80 \mu \mathrm{M})$, and dopamine $(80-160 \mu \mathrm{M})$ in all hindlimb preparations $(n=12)$.

Figure 6B1 shows a schematic of the episodic pattern, consisting of discharge episodes and no discharge episodes, based on the results shown in Figures 2, 4A (high flow rate, decerebrate, and arterially perfused preparation). Figure $6 \mathrm{~B} 2$ is a schematic of the episodic pattern based on the results shown in Figure 6A induced by the administration of the drugs to the hindlimb preparation. The episodic periods (discharge episodes containing rhythmic and burst-like activity) and the silent periods (no discharge episodes) in each preparation were produced simultaneously and repeatedly on both sides. These results suggest that the discharge episodes in the left and right peripheral motor nerves originated in the lower spinal cord and not the brainstem.

\section{The mechanisms of induction of the phrenic nerve discharge during discharge episodes}

To confirm whether the phrenic nerve discharge episodes occurring during discharge episodes relies on impulses originating in the lower spinal cord, instances of phrenic and the tibial nerve discharge were recorded at flow rates of $<10 \times \mathrm{TBV} / \mathrm{min}$ in a decerebrate and arterially perfused in situ preparation at postnatal day 16 , spinalized at the twelfth thoracic vertebra to sever signal transmission to the brainstem from the lower spinal cord. When discharge episodes were periodically produced in the phrenic and tibial nerves, the same phase relationship between the phrenic and tibial nerve discharge, as that in Figure 4B, was seen in discharge episodes even after spinalization, but at the mean (SE) incidence per minute that was 52.62 (11.96) \% lower $(P<0.001)$ (Figures 7A,B). In addition, the respiratory rhythm after spinalization was more regular than before. Although the episode discharge might be originated from the brainstem and the upper spinal cord, these results (obtained in each of three preparations), indicated that the locomotor-like discharge generated in the lower spinal cord produced a rapid phrenic discharge via ascending pathways and entrained the respiratory rhythm to the locomotor rhythm. They also suggest that a time lag of $\approx 400 \mathrm{~ms}$ is the time necessary for the impulse to travel from the lower spinal cord to the brainstem respiratory network via ascending pathways and then to the phrenic nerve via descending pathways.

\section{DISCUSSION}

The present study used extracellular recordings to investigate the neural pathways driving respiration and locomotion in a decerebrate and arterially perfused in situ mouse preparation. The results indicate that sympathetic tone modulated by a hyperoxic/normocapnic state activates the LPG through descending pathways and produces a locomotor-like discharge in the hindlimb (Figure 8A). After initiating this locomotor-like discharge, the generation of a locomotor-like discharge in the lower spinal cord acts on the brainstem respiratory center through ascending pathways to synchronize respiratory and locomotor rhythms (Figure 8B). These results indicate that (i) locomotion can be generated under specific respiratory conditions induced by hyperoxia/normocapnia and (ii) a spinal-feedback mechanism generating a locomotor-like discharge in the lower spinal cord is the principal mechanism in the entrainment of respiratory and locomotor rhythms. The existence of this mechanism implies: (i) that there is an autonomous reciprocal functional interaction between respiration and locomotion and (ii) that an increase in respiratory rate during locomotion is caused both by impulses from the lower spinal cord (which produces a locomotor-like discharge via ascending pathways), and afferent input received from mechanoreceptors and nociceptors.

\section{SYMPATHETIC/PARASYMPATHETIC TONE OF THE DECEREBRATE AND ARTERIALLY PERFUSED IN SITU PREPARATION}

In the present study, the oxygen and ion components of body fluid required for the survival of the preparation were supplied by 


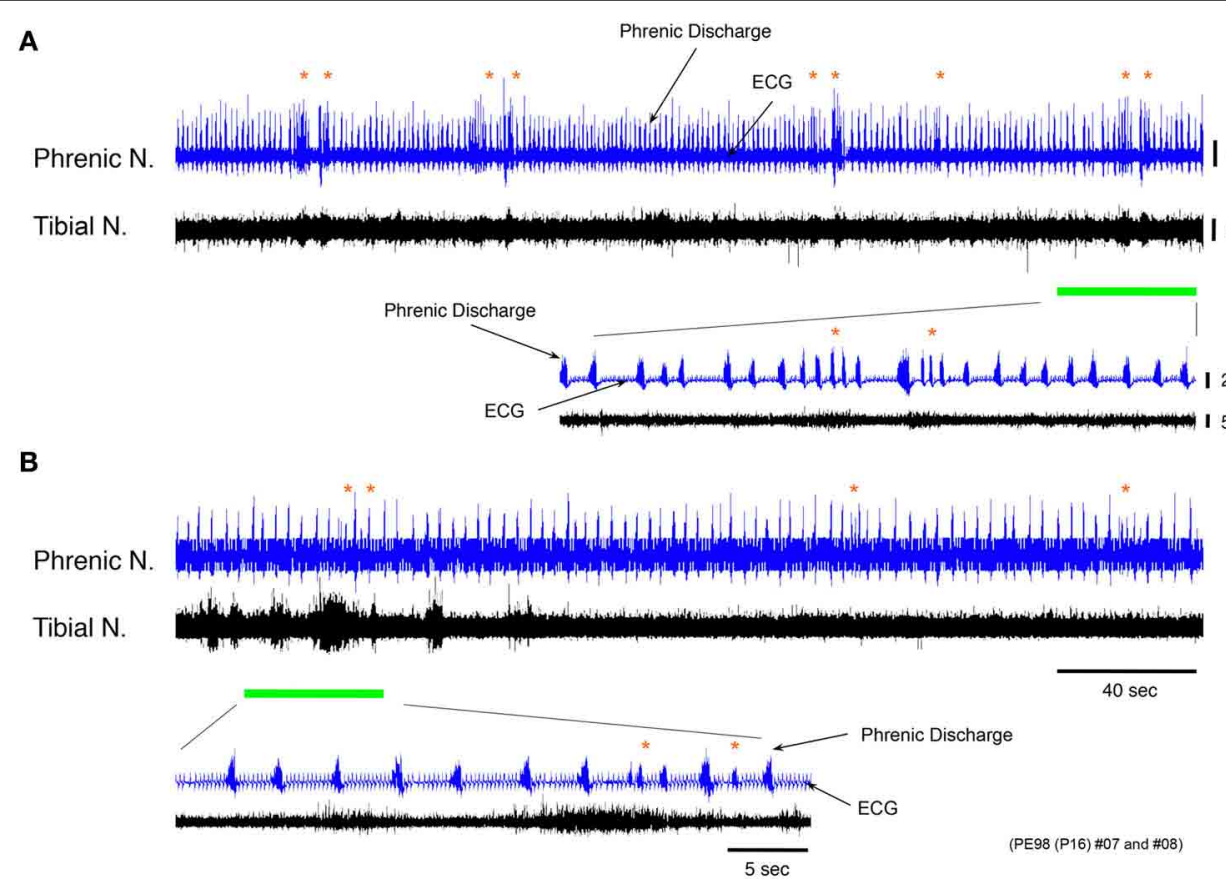

FIGURE 7 | Recordings of experimental trials showing changing incidence of phrenic discharge episodes before and after spinalization. $(\mathbf{A}, \mathbf{B})$ Recordings showing phrenic and tibial nerve discharge induced before and after spinalization of a decerebrate and arterially perfused in situ preparation made at postnatal day 16 at the twelfth thoracic vertebra level at a flow rate of $<\times 10 \mathrm{TBV} / \mathrm{min}$. After spinalization, the frequency of phrenic discharge dramatically decreased and the mean (SE) incidence of phrenic discharge episodes per minute was 52.62 (11.96) \% lower $(P<0.001)$. The respiratory rhythm after spinalization was regular compared with that before. The same result was obtained for all preparations $(n=3)$. the perfusate via the blood vessels, while body temperature was maintained at room temperature. When the flow rate was high enough to produce a systemic pressure of $>30 \mathrm{mmHg}$, the preparation showed spontaneous respiration, and when the perfusion flow rate was set at $>5 \times \mathrm{TBV} / \mathrm{min}$, the phrenic discharge showed a "eupneaic pattern" and "regular rhythm."

The tip of the double-lumen catheter was held in the ascending aorta by the aortic valve and the internal pressure of the heart was maintained at atmospheric pressure. The lungs were completely removed. Thus, the effect of afferent input from mechanosensors of the heart wall (Bishop et al., 1983; Hainsworth, 1991; Hines et al., 1994), glomus type I cells on the carotid body that detect thermal changes (Alcayaga et al., 1993), and stretch receptors of the lung (Kalia and Sullivan, 1982; Hines et al., 1994) could be ignored. Because baroreflex-mediated parasympathetic/sympathetic control of vessel resistance is affected by pulsatile rather than non-pulsatile flow (James and de Burgh Daly, 1970; Chapleau et al., 1989), a peristaltic pump was used to provide a pressure pulse wave to the baroreceptors of the preparation, with $\mathrm{pH}$ before and after systemic perfusion continuously maintained within the physiological range. However, the preparation was gradually exposed to a hyperoxic/normocapnic state by increasing the flow rates (Figure 5). Simultaneously, the balance of the sympathetic/parasympathetic tone of the preparation broke down and the sympathetic tone was easily modulated. Thus, the decrease in heart rate shown in Figure 3B might have been induced because the sympathetic tone was modulated by the hyperoxic/normocapnic state. From the data obtained under these conditions, it appears that the sympathetic/parasympathetic tone of the preparation had been affected by the reception of afferent input from both the baroreceptors of the aortic bodies (James and de Burgh Daly, 1970; Chapleau et al., 1989), and the peripheral chemoreceptors of the carotid bodies (Nattie, 1998), although the sympathetic/parasympathetic tone increased with an increase in the flow rate. The results also indicate that the systemic pressure changes (Figure 2A) reflects not only changes in flow rate but also vasoconstriction and vasodilatation of both the arteries and the arterioles, which are controlled by sympathetic tone (Coleridge and Coleridge, 1980; Julius and Nesbitt, 1996).

In adult mice, the volume of blood circulated in a minute at rest is equal to the entire blood volume (Yang et al., 1999). Metabolism depends on both body temperature and perfusion flow rates: less oxygen is consumed at low body temperatures and high flow rates than at high body temperatures (Fox et al., 1982; Kirklin and Barratt-Boyes, 1993). Despite this, the 95\% $\mathrm{O}_{2} / 5 \% \mathrm{CO}_{2}$-infused perfusate used in the present study is clearly an inferior oxygen carrier compared with hemoglobin. Therefore, the experiments were performed at room temperature at a high flow rate to increase the amount of oxygen conveyed by the perfusate and minimize metabolism. When conducted in this manner, the systemic pressure of the preparation was much lower than that in vivo. This difference might be attributed to the following factors: (i) the deep hypothermia under which the preparation was examined (i.e., at room temperature), which led 


\section{A}

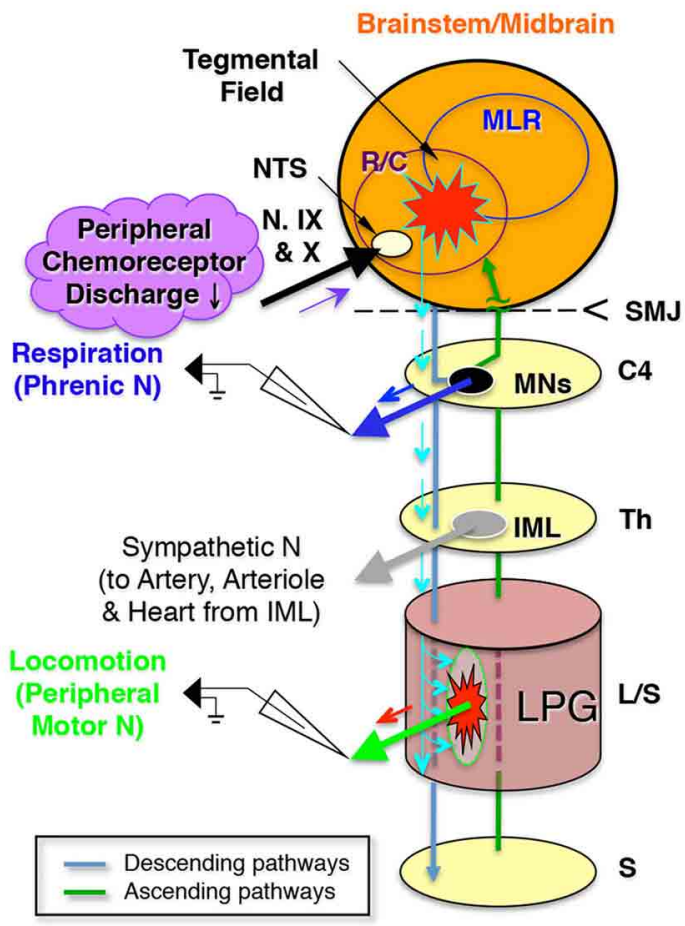

B

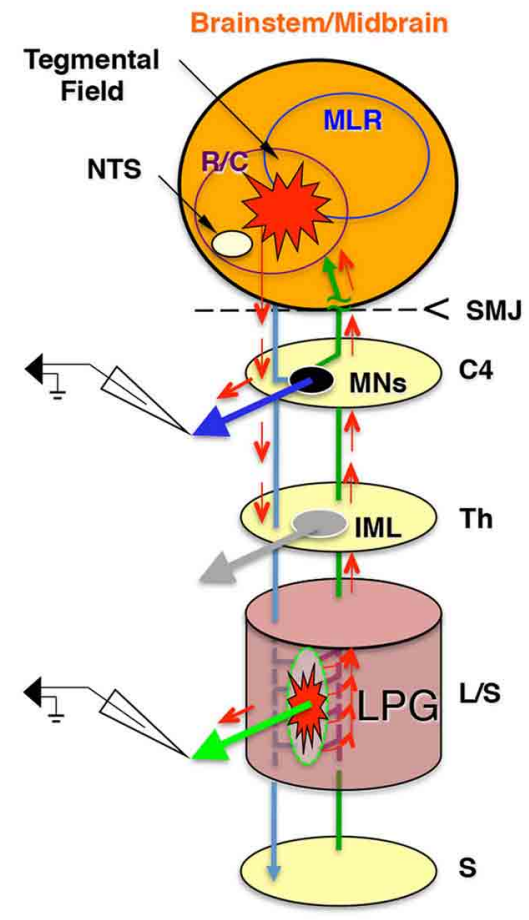

Abbreviations: NTS; The Nucleus of the Tractus Solitarius, R/C; Respiratory/Circulatory center, MLR; Mesencephalic Locomotor Region, SMJ; Spino-Medullary Junction, N. IX; Glossopharyngeal nerve (containing carotid sinus nerve), N. X; Vagal nerve containing Aortic N., C4; the $4^{\text {th }}$ Cervical spinal cord, Th; Thoracic spinal cord, IML; Intermediolateral nucleus, L/S; Lumber/Sacral spinal cord, LPG; Locomotor Pattern Generator

FIGURE 8 | Schematic representation of (A). The modulated sympathetic tone generating fictive locomotion via descending pathways and (B) The locomotor rhythm that entrains the respiratory rhythm via ascending pathways during locomotion.

sympathetic tone to be extremely low; (ii) that despite increasing with increasing flow rate, the sympathetic tone seen at each high flow rate was easily modulated by afferent input from the peripheral chemoreceptors (Figure 2B), leading to a decrease in systemic blood pressure due to the hyperoxic state (Mokashi and Lahiri, 1991); (iii) the lack of viscoelasticity of the perfusate, compared with that of blood; and (iv) the leaking of perfusate from damaged capillaries and vessels when the preparation had been decerebrated and the skin systemically peeled. Furthermore, arginine vasopressin acts at V1 receptors to mediate vasoconstriction of peripheral blood vessels (Martin de Aguiler et al., 1990; Medina et al., 1998), changing the constrictor activity of the peripheral sympathetic nervous system (Bartelstone and Nasmyth, 1965). So the absence of arginine vasopressin from the perfusate, could also have played a role in the lower systematic respiration of the preparation compared with that in vivo.

The respiratory rhythm of the preparation was irregular not only compared with that in vivo, but also that of the in situ rat preparation of Pickering and Paton (2006). A hypothesis about the mechanism behind the induction of an irregular respiratory rhythm can be developed in accordance with the observation that the discharge episodes consisting of instances of left-right rhythmic or burst-like activity were generated in both the upper and the lower spinal cord at most of the flow rates tested. Consequently, the generation of the left-right alternating discharge in both the upper and the lower spinal cord affected the capability of the respiratory center to generate a regular respiratory rhythm, inducing an irregular respiratory rhythm.

\section{CONCLUSION}

The findings of the present study indicate that specific respiratory conditions can generate locomotor-like discharge in the hindlimbs of mice. After a locomotor-like discharge is generated in the lower spinal cord, the LPG generating a locomotor-like discharge acts on the brainstem respiratory center through ascending pathways and thereby facilitates synchronization of the respiratory and locomotor rhythms. These results show that there are autonomous functions of respiration and locomotion. In addition, the increase in respiratory rate seen during locomotion is caused not only by reception of afferent input from mechanoreceptors and nociceptors but also from impulses from the lower spinal cord that produces a locomotor-like discharge via ascending pathways.

\section{AUTHOR CONTRIBUTIONS}

Itaru Yazawa designed the study, analyzed the data, and wrote the paper. 


\section{ACKNOWLEDGMENTS}

This work was supported by the intramural program of the National Institute of Neurological Disorders and Stroke. I thank Dr. A. E. Pickering for his helpful comments regarding the manuscript.

\section{REFERENCES}

Ainsworth, D. M., Smith, C. A., Henderson, K. S., and Dempsey, J. A. (1996). Breathing during exercise in dogs-passive or active? J. Appl. Physiol. 81, 586-595.

Alcayaga, J., Sanhueza, Y., and Zapata, P. (1993). Thermal dependence of chemosensory activity in the carotid body superfused in vitro. Brain Res. 600, 103-111. doi: 10.1016/0006-8993(93)90407-E

Ballantyne, D., and Scheid, P. (2001). Central chemosensitivity of respiration: a brief overview. Respir. Physiol. 129, 5-12. doi: 10.1016/S0034-5687(01)00297-3

Barman, S. M., and Gebber, G. L. (1976). Basis for synchronization of sympathetic and phrenic nerve discharges. Am. J. Physiol. 231, 1601-1607.

Bartelstone, H. J., and Nasmyth, P. A. (1965). Vasopressin potentiation of catecholamine actions in dog, rat, cat and rat aortic strip. Am. J. Physiol. 208, 754-762.

Bishop, V. S., Malliani, A., and Thorén, P. (1983). “Cardiac mechanoreceptors," in Handbook of Physiology, Vol. 2, eds E. Page, H. A. Fozzard, and R. J. Solaro (Bethesda, MD: American Physiological Society), 497-555.

Bramble, D. M., and Carrier, D. R. (1983). Running and breathing in mammals. Science 219, 251-256. doi: 10.1126/science.6849136

Brice, A. G., Forster, H. V., Pan, L. G., Funahashi, A., Hoffman, M. D., Murphy, C. L., et al. (1988). Is the hyperpnea of muscular contractions critically dependent on spinal afferents? J. Appl. Physiol. 64, 226-233.

Bromley, D. V., and Holdstock, T. L. (1969). Effects of septal stimulation on heart rate in vagotomized rats. Physiol. Behav. 4, 3. doi: 10.1016/0031-9384(69) 90197-8

Brown, D. R., Forster, H. V., Pan, L. G., Brice, A. G., Murphy, C. L., Lowry, T. F., et al. (1990). Ventilatory response of spinal cord lesioned subjects to electrically induced exercise. J. Appl. Physiol. 68, 2312-2321.

Chapleau, M. W., Hajduczok, G., and Abboud, F. M. (1989). Pulsatile activation of baroreceptors causes central facilitation of baroreflex. Am. J. Physiol. 256, H1735-H1741.

Chizh, B. A., Headley, P. M., and Paton, J. F. (1997). An arterially-perfused trunkhindquarters preparation of adult mouse in vitro. J. Neurosci. Methods 76, 177-182. doi: 10.1016/S0165-0270(97)00096-4

Coleridge, H. M., and Coleridge, J. C. (1980). Cardiovascular afferents involved in regulation of peripheral vessels. Annu. Rev. Physiol. 42, 413-427. doi: 10.1146/annurev.ph.42.030180.002213

Corio, M., Palisses, R., and Viala, D. (1993). Origin of the central entrainment of respiration by locomotion facilitated by MK 801 in the decerebrate rabbit. Exp. Brain. Res. 95, 84-90. doi: 10.1007/BF00229657

Dejours, P. (1967). Neurogenic factors in the control of ventilation during exercise. Circ. Res. 20/21(Suppl. 1), I146-I153.

Eldridge, F. L., Millhorn, D. E., and Waldrop, T. G. (1981). Exercise hyperpnea and locomotion: parallel activation from the hypothalamus. Science 211, 844-846. doi: $10.1126 /$ science. 7466362

Fox, L. S., Blackstone, E. H., Kirklin, J. W., Stewart, R. W., and Samuelson, P. N. (1982). Relationship of whole body oxygen consumption to perfusion flow rate during hypothermic cardiopulmonary bypass. J. Thorac. Cardiovasc. Surg. 83, 239-248.

Giraudin, A., Le Bon-Jégo, M., Cabirol, M., Simmers, J., and Morin, D. (2012). Spinal and pontine relay pathways mediating respiratory rhythm entrainment by limb proprioceptive inputs in the neonatal rat. J. Neurosci. 32, 11841-11853. doi: 10.1523/JNEUROSCI.0360-12.2012

Hainsworth, R. (1991). Reflexes from the heart. Physiol. Rev. 71, 617-658.

Harkness, J. E., and Wagner, J. E. (1989). "Biology and husbandry," in The Biology and Medicine of Rabbits and Rodents, eds J. E. Harkness and J. E. Wagner (Philadelphia, PA: Lea \& Febiger), 372.

Hines, T., Toney, G. M., and Mifflin, S. W. (1994). Responses of neurons in the nucleus tractus solitarius to stimulation of heart and lung receptors in the rat. Circ. Res. 74, 1188-1196. doi: 10.1161/01.RES.74.6.1188

Iscoe, S. (1981). Respiratory and stepping frequencies in conscious exercising cats. J. Appl. Physiol. 51, 835-839.
James, J. E., and de Burgh Daly, M. (1970). Comparison of the reflex vasomotor responses to separate and combined stimulation of the carotid sinus and aortic arch baroreceptors by pulsatile and non-pulsatile pressures in the dog. J. Physiol. 209, 257-293.

Julius, S., and Nesbitt, S. (1996). Sympathetic overactivity in hypertension. A moving target. Am. J. Hypertens. 9, 113S-120S. doi: 10.1016/0895-7061(96)00287-7

Kalia, M., and Sullivan, J. M. (1982). Brainstem projections of sensory and motor components of the vagus nerve in the rat. J. Comp. Neurol. 211, 248-265. doi: $10.1002 / \mathrm{cne} .902110304$

Kirklin, J. W., and Barratt-Boyes, B. G. (1993). "Hypothermia, circulatory arrest, and cardiopulmonary bypass," in Cardiac Surgery, eds J. W. Kirklin and B. G. Barratt-Boyes (New York, NY: Churchill Livingstone), 61-127.

Krogh, A., and Lindhard, J. (1913). The regulation of respiration and circulation during the initial stages of muscular work. J. Physiol. 47, 112-136.

Loeschcke, H. H. (1982). Central chemosensitivity and the reaction theory. J. Physiol. 332, 1-24.

Manning, J. W., Charbon, G. A., and Cotton, M. D. (1963). Inhibition of tonic cardiac sympathetic activity by stimulation of brain septal region. Am. J. Physiol. 205, 1221-1226.

Martin de Aguiler, E., Vila, J. M., Irurzun, A., Martinez, M. C., Martinez Cuesta, M. A., and Lluch, S. (1990). Endothelium-independent contractions of human cerebral arteries in response to vasopressin. Stroke 21, 1689-1693. doi: 10.1161/01.STR.21.12.1689

Medina, P., Acuna, A., Martinez-Leon, J. B., Otero, E., Vila, J. M., Aldasoro, M., et al. (1998). Arginine vasopressin enhances sympathetic constriction through the V1 vasopressin receptor in human saphenous vein. Circulation 97, 865-870. doi: 10.1161/01.CIR.97.9.865

Mitruka, B. M., and Rawnsley, H. M. (1981). Clinical Biochemical and Hematological Reference Values in Normal Experimental Animals and Normal Humans. New York, NY: Masson.

Mokashi, A., and Lahiri, S. (1991). Aortic and carotid body chemoreception in prolonged hyperoxia in the cat. Respir. Physiol. 86, 233-243. doi: 10.1016/00345687(91)90083-U

Mor, Y., and Lev-Tov, A. (2007). Analysis of rhythmic patterns produced by spinal neural networks. J. Neurophysiol. 98, 2807-2817. doi: 10.1152/jn.00740.2007

Nattie, 1998. "Central chemoreceptors, $\mathrm{pH}$, and respiratory control," in $\mathrm{pH}$ and Brain Function, eds K. Kaila and B. R. Ransom (New York, NY: Wiley-Liss, Inc.), 535-560.

O’Regan, R. G., and Majcherczyk, S. (1982). Role of peripheral chemoreceptors and central chemosensitivity in the regulation of respiration and circulation. J. Exp. Biol. 100, 23-40.

Pickering, A. E., and Paton, J. F. (2006). A decerebrate, artificially-perfused in situ preparation of rat: utility for the study of autonomic and nociceptive processing. J. Neurosci. Methods 155, 260-271. doi: 10.1016/j.jneumeth.2006.01.011

Potts, J. T., Rybak, I. A., and Paton, J. F. (2005). Respiratory rhythm entrainment by somatic afferent stimulation. J. Neurosci. 25, 1965-1978. doi: 10.1523/JNEUROSCI.3881-04.2005

Whelan, P., Bonnot, A., and O'Donovan, M. J. (2000). Properties of rhythmic activity generated by the isolated spinal cord of neonatal mouse. J. Neurophysiol. 84, 2821-2833.

Yang, B., Larson, D. F., and Watson, R. (1999). Age-related left ventricular function in the mouse: analysis based on in vivo pressure-volume relationships. Am. J. Physiol. 277, H1906-H1913.

Conflict of Interest Statement: The author declares that the research was conducted in the absence of any commercial or financial relationships that could be construed as a potential conflict of interest.

Received: 10 February 2014; accepted: 07 May 2014; published online: 30 May 2014. Citation: Yazawa I (2014) Reciprocal functional interactions between the brainstem and the lower spinal cord. Front. Neurosci. 8:124. doi: 10.3389/fnins.2014.00124 This article was submitted to Autonomic Neuroscience, a section of the journal Frontiers in Neuroscience.

Copyright (C) 2014 Yazawa. This is an open-access article distributed under the terms of the Creative Commons Attribution License (CC BY). The use, distribution or reproduction in other forums is permitted, provided the original author(s) or licensor are credited and that the original publication in this journal is cited, in accordance with accepted academic practice. No use, distribution or reproduction is permitted which does not comply with these terms. 